\title{
The Effect of Manganese Substituted $M$-type Hexagonal Ba-ferrite
}

\author{
In Kyu Lee ${ }^{1}$, Jung Chul Sur ${ }^{2}$, In-Bo Shim ${ }^{1}$, and Chul Sung Kim ${ }^{1 *}$ \\ ${ }^{1}$ Department of Physics, Kookmin University, Seoul 136-702, Korea \\ ${ }^{2}$ Department of Microelectronics and Display Technology, Wonkwang University, Iksan 570-749, Korea
}

(Received 15 January 2009, Received in final form 3 April 2009, Accepted 8 April 2009)

\begin{abstract}
The Mn-substituted $M$-type Ba-ferrite $\left(\mathrm{BaFe}_{12-x} \mathrm{Mn}_{x} \mathrm{O}_{19} ; x=0,2,4,6\right)$ powders were prepared by the HTTD (High Temperature Thermal Decomposition) method. The effect of $\mathrm{Mn}^{3+} \mathrm{Jahn}^{3}$ Teller ions on the magnetic properties has been studied by $x$-ray diffraction, vibrating sample magnetometry, and Mössbauer spectroscopy. With increasing Mn substitution, the lattice parameter $a_{0}$ increases while $c_{0}$ decreases. The magnetocrystalline anisotropy constants $\left(K_{1}\right)$ were determined as $2.9,2.2,1.8$, and, $1.3 \times 10^{6} \mathrm{erg} / \mathrm{cm}^{3}$ for $x=0,2,4$, and 6 , respectively, by the LAS method. We have studied the change of cation distribution by Mössbauer spectroscopy which is closely related to $K_{1}$.
\end{abstract}

Keywords : Ba-ferrite, Mössbauer spectra, magnetocrystalline anisotropy, cation distribution

\section{Introduction}

$M$-type hexaferrite $M \mathrm{Fe}_{12} \mathrm{O}_{19}(M=\mathrm{Ba}, \mathrm{Sr}, \mathrm{Pb}, \mathrm{La})$ has been intensively investigated for use as a high density perpendicular magnetic recording media, as a permanent magnet, and as a microwave absorption device $[1,2]$ because of its suitable coercivity, high magnetocrystalline anisotropy, and high chemical stability. Cation such as $\mathrm{Al}^{3+}, \mathrm{Cr}^{3+}, \mathrm{Co}^{2+}-\mathrm{Ti}^{4+}, \mathrm{Co}^{2+}-\mathrm{Sn}^{4+}$, and $\mathrm{Zn}^{2+}-\mathrm{Zr}^{4+}$ were substituted for $\mathrm{Fe}^{3+}$ to control its coercivity and magnetic properties [3-7]. The structure of the barium ferrite is symbolically described as $R S R^{*} S^{*}$, where $R$ is a threelayer block (two $\mathrm{O}_{4}$ containing one $\mathrm{BaO}_{3}$ ) with the composition $\mathrm{Ba}^{2+} \mathrm{Fe}^{3+}{ }_{6} \mathrm{O}^{2-}{ }_{11}$, and $S$ is a two $\mathrm{O}^{2-}$-layer block with the composition $\mathrm{Fe}^{3+}{ }_{6} \mathrm{O}^{2-}$, where the asterisk means that the corresponding block has been turned $180^{\circ}$ around the hexagonal $c$ axis. The $\mathrm{Fe}^{3+}$ ions are arranged in five different kinds of interstitial sites, of which three are octahedral sites $\left(12 k, 4 f_{2}\right.$, and $\left.2 a\right)$, one is a tetrahedral site $\left(4 f_{1}\right)$, and one is a site in which the ferric ion is surrounded by five oxygen atoms forming a trigonal bipyramid $(2 b)$.

In this paper, we report on the site occupation, as determined by Mössbauer spectroscopy, and the magnetocrystalline anisotropy of a $\mathrm{Mn}^{3+} \mathrm{Jahn}-$ Teller ion substitut-

*Corresponding author: Tel: +82-2-910-4752

Fax: +82-2-910-5170, e-mail: cskim@phys.kookmin.ac.kr ed $\mathrm{BaFe}_{12-x} \mathrm{Mn}_{x} \mathrm{O}_{19}(0.0 \leq x \leq 6.0)$.

\section{Experiments}

Manganese substituted Ba-ferrite polycrystalline powders were prepared by the HTTD (High Temperature Thermal Decomposition) method [8]. $\mathrm{Ba}(\mathrm{acac})_{2}\left[\left(\mathrm{C}_{5} \mathrm{H}_{8} \mathrm{O}_{2}\right)_{2} \mathrm{Ba} \cdot \mathrm{xH}_{2} \mathrm{O}\right]$, $\mathrm{Fe}(\mathrm{acac})_{3}\left[\left(\mathrm{C}_{5} \mathrm{H}_{8} \mathrm{O}_{2}\right)_{3} \mathrm{Fe}\right]$, and $\mathrm{Mn}(\mathrm{acac})_{3}\left[\left(\mathrm{C}_{5} \mathrm{H}_{8} \mathrm{O}_{2}\right)_{3} \mathrm{Mn}\right]$ were used as starting materials. These were dissolved in oleylamine, with the stoichiometric ratio of $\mathrm{Ba} /(\mathrm{Fe}, \mathrm{Mn})$ $=1 / 12$. The solution was refluxed at $330^{\circ} \mathrm{C}$ for $1 \mathrm{~h}$ under $\mathrm{Ar}$, and was subsequently dried at $60^{\circ} \mathrm{C}$. Finally, the precursor powders were sintered at 950 , and $1050^{\circ} \mathrm{C}$ for 6 $h$ in air.

The crystal structure of the samples was examined by x-ray diffraction with $\mathrm{Cu} K \alpha$ radiation $(\lambda=1.5406 \AA)$. The temperature dependence of magnetization was measured by VSM with a maximum field of up to $10 \mathrm{kOe}$ in a 50-780 $\mathrm{K}$ temperature range and the hysteresis loops under $15 \mathrm{kOe}$ were also measured. In order to observe the magnetic hyperfine interactions of iron ions in five sublattices of Ba-ferrite, Mössbauer spectra were recorded with a $40 \mathrm{mCi}{ }^{57} \mathrm{Co}$ source in an $\mathrm{Rh}$ matrix.

\section{Results and Discussion}

Fig. 1 shows the x-ray diffraction patterns of the Mnsubstituted $\mathrm{BaFe}_{12-x} \mathrm{Mn}_{x} \mathrm{O}_{19}(0.0 \leq x \leq 6.0)$ at room temper- 


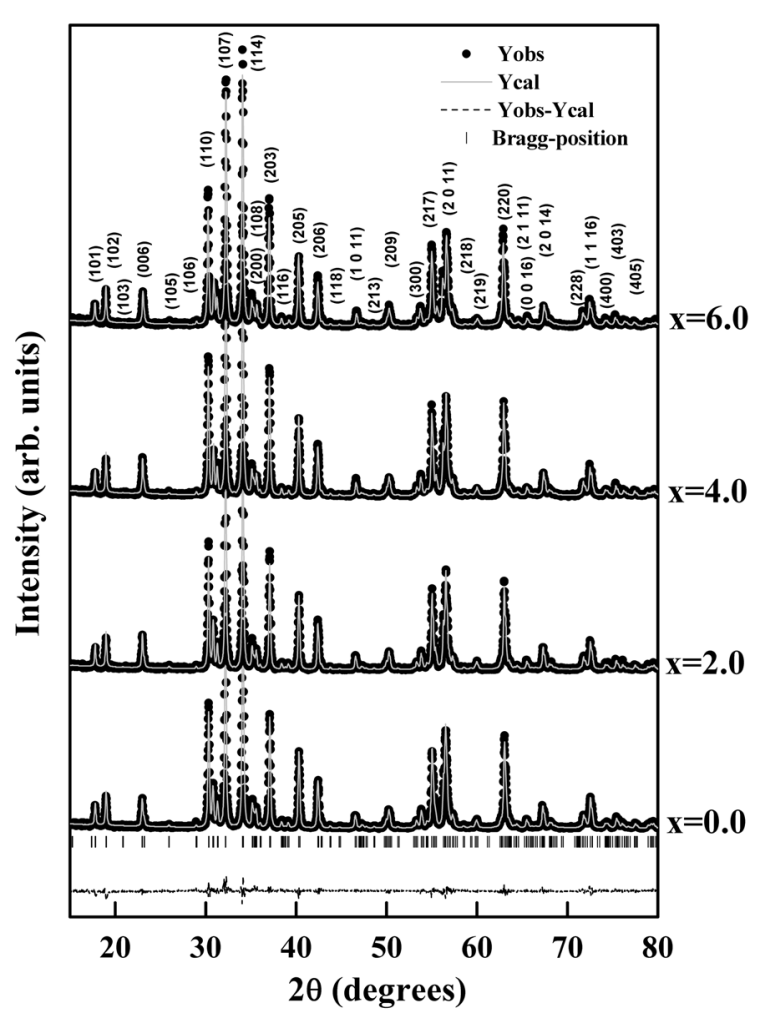

Fig. 1. Refined x-ray diffraction data of $\mathrm{BaFe}_{12-x} \mathrm{Mn}_{x} \mathrm{O}_{19}$ at room temperature. The solid circles, continuous lines, and the dotted line represent the observed, the calculated, and the difference (obs-cal) profiles, respectively. Tick marks represent the Bragg position of the reflections.

ature. An analysis of x-ray diffraction patterns by the Rietveld refinement method using the FULLPROF program showed that all samples of $\mathrm{BaFe}_{12-x} \mathrm{Mn}_{x} \mathrm{O}_{19}$ had a magnetoplumbite hexagonal structure with the space group $\mathrm{P6}_{3} / m m c$ as shown in Fig. 1. The refined x-ray diffraction parameters, lattice constant, volume of unit cell $(V)$, and x-ray density $\left(\rho_{x}\right)$ at room temperature for $\mathrm{BaFe}_{12-x} \mathrm{Mn}_{x} \mathrm{O}_{19}$ are presented in Table 1. As the Mn substitution increases, the lattice constant $a_{o}$ and $V$ increases, while $c_{o}$ and the xray density $\rho_{x}$ decreases. This can be expected when considering that the ionic radius of $0.66 \AA$ for the $\mathrm{Mn}^{3+}$ ions is larger than that of the $0.64 \AA$ for $\mathrm{Fe}^{3+}$ ions. Also, the hexagonal crystal structure is distorted, as though it were expanded along the $a$-axis by the effect of $\mathrm{Mn}^{3+}$ ions distribution.

With an increasing $x$, the saturation magnetization, $M_{s}$ is obviously decreased with $47.4,30.4$, and $15.0 \mathrm{emu} / \mathrm{g}$ for $x=2.0,4.0$, and 6.0. However, the coercivity, $H_{c}$ is slightly decreased at $x=2.0$, and then greatly increased over $x=2.0$ as shown in Table 2. The $\mathrm{BaFe}_{6} \mathrm{Mn}_{6} \mathrm{O}_{19}$ shows a very high $H_{c}$ of 8,207 Oe. Fig. 2 shows the temperature dependence of the zero field cooled (ZFC)
Table 1. Refined x-ray diffraction parameters of $\mathrm{BaFe}_{12-x} \mathrm{Mn}_{x}$ $\mathrm{O}_{19}$. Here, $a_{o}$ and $c_{o}$ are lattice parameters, $V$ is the volume of the unit cell, and $\rho_{x}$ is the X-ray density

\begin{tabular}{clrrrc}
\hline \hline$x$ & $a_{o}(\AA)$ & $c_{o}(\AA)$ & $c_{o} / a_{o}$ & $V\left(\AA^{3}\right)$ & $\rho_{x}\left(\mathrm{~g} / \mathrm{cm}^{3}\right)$ \\
\hline 0.0 & 5.894 & 23.214 & 3.949 & 698.378 & 5.285 \\
2.0 & 5.896 & 23.191 & 3.934 & 698.116 & 5.278 \\
4.0 & 5.9 & 23.169 & 3.927 & 698.502 & 5.267 \\
6.0 & 5.905 & 23.137 & 3.918 & 698.736 & 5.257 \\
\hline
\end{tabular}

Table 2. The saturation magnetization $M_{\mathrm{s}}, H_{\mathrm{c}}$ is the coercivities, $K_{1}$ is the magnetocrystalline anisotropy constants, and $H_{\mathrm{A}}$ is the anisotropy field of $\mathrm{BaFe}_{12-x} \mathrm{Mn}_{x} \mathrm{O}_{19}$

\begin{tabular}{ccccc}
\hline \hline$x$ & $M_{\mathrm{s}}(\mathrm{emu} / \mathrm{g})$ & $H_{\mathrm{c}}(\mathrm{Oe})$ & $K_{1}\left(\times 10^{6} \mathrm{erg} / \mathrm{cm}^{3}\right)$ & $H_{\mathrm{A}}(\mathrm{kOe})$ \\
\hline 0.0 & 61.7 & 5,944 & 2.9 & 16.2 \\
2.0 & 47.4 & 5,758 & 2.2 & 16.3 \\
4.0 & 30.4 & 6,277 & 1.8 & 19.0 \\
6.0 & 15.0 & 8,207 & 1.3 & 27.2 \\
\hline
\end{tabular}

magnetization curves with a $10 \mathrm{kOe}$ applied field in the temperature range of $50-780 \mathrm{~K}$. In the $\mathrm{ZFC}$ curve, the magnetization decreases steadily with an increase in temperature up to the Curie temperature. The Curie temperature is obtained by the $d M / d T$ curves of the ZFC. As the $\mathrm{Mn}^{3+}$ substitution increased, the Curie temperature decreased. The decrease of the Curie temperature means that the $\mathrm{Mn}^{3+}-\mathrm{O}^{2-}-\mathrm{Fe}^{3+}$ super-exchange interaction is weaker than the $\mathrm{Fe}^{3+}-\mathrm{O}^{2-}-\mathrm{Fe}^{3+}$ super-exchange interaction.

The magnetocrystalline anisotropy constant $K_{1}$ and anisotropy field $H_{\mathrm{a}}$ of $\mathrm{BaFe}_{12-x} \mathrm{Mn}_{x} \mathrm{O}_{19}$ were determined by the law of approach to saturations (LAS) method. The LAS method can be described as [9].

$$
M=M_{s}\left(1-\frac{A}{H}-\frac{B}{H^{2}}-\frac{C}{H^{3}}-\cdots\right)+\chi_{P} H
$$

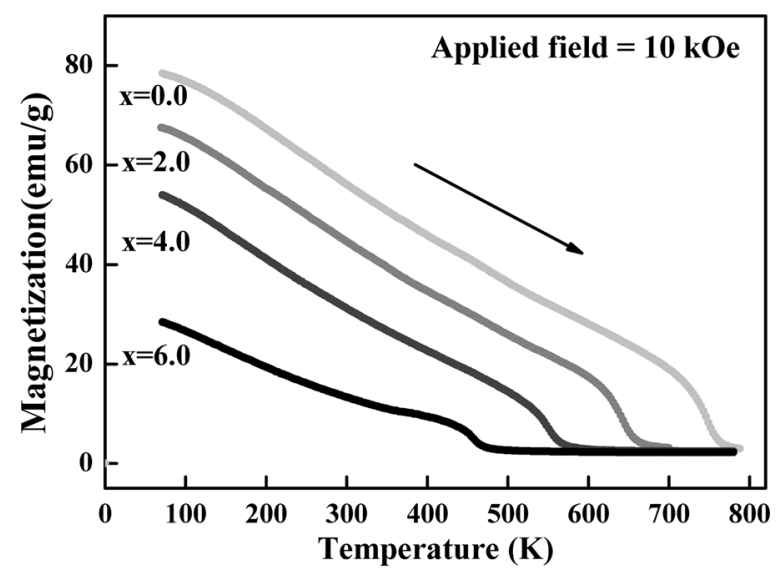

Fig. 2. Temperature dependence of zero field cooled magnetization curves of $\mathrm{BaFe}_{12-x} \mathrm{Mn}_{x} \mathrm{O}_{19}$. 
Here, $A$ is the inhomogeneity parameter, $B$ is the anisotropy parameter, and $\chi_{p}$ is the paramagnetic susceptibility at high fields, where the saturation magnetization $M_{s}$ and $B$ is the magnetization dependent process parameter such as

$$
B=\frac{H_{A}^{2}}{15}=\frac{4 K_{1}^{2}}{15 M_{S}^{2}}
$$

The anisotropy constant $K_{1}$ and the anisotropy field $H_{\mathrm{a}}$ can be obtained by fitting the magnetization curve using Eqs. (1) and (2). Table 2 shows the magnetocrystalline anisotropy constants $\left(K_{1}\right)$ and the anisotropy field $\left(H_{\mathrm{a}}\right)$ of $\mathrm{BaFe}_{12-x} \mathrm{Mn}_{x} \mathrm{O}_{19}$ with various $\mathrm{Mn}$ concentrations. With an increase of the Mn concentration $x, K_{1}$ is linearly reduced, and $H_{\mathrm{a}}$ is simultaneously increased. In Ba-ferrite, the $12 k$ and $2 b$ sublattices $\mathrm{Fe}^{3+}$ ions could contribute to the overall uniaxial anisotropy [4]. Therefore, a reduced occupancy of spin-up (12k) and spin-down $\left(4 f_{2}\right)$ sites could explain the relative reduction of magnetocrystalline anisotropy. This is due to the decrease of the number of $N_{\mathrm{Fe}}(i)$ in the $12 k$ site with an increase of $x$.

Fig. 3 shows the Mössbauer spectra of $\mathrm{BaFe}_{12-x} \mathrm{Mn}_{x} \mathrm{O}_{19}$ $(0.0 \leq x \leq 6.0)$ at $200 \mathrm{~K}$. All spectra were fitted with five six-line sub patterns corresponding to the $4 f_{2}, 2 a, 4 f_{1}, 12 k$, and $2 b$ sites of the $M$-type hexagonal structure for the site occupancy and hyperfine interaction of Fe ions. From the relative areas, $S(i) i=1-5$, the site occupation numbers of $\mathrm{Fe}^{3+}\left(N_{\mathrm{Fe}}(i)\right)$ and $\mathrm{Mn}$ ions $\left(N_{\mathrm{Mn}}(i)\right)$ on the $i$ th site can be determined based on Eqs. (3) and (4) [7].

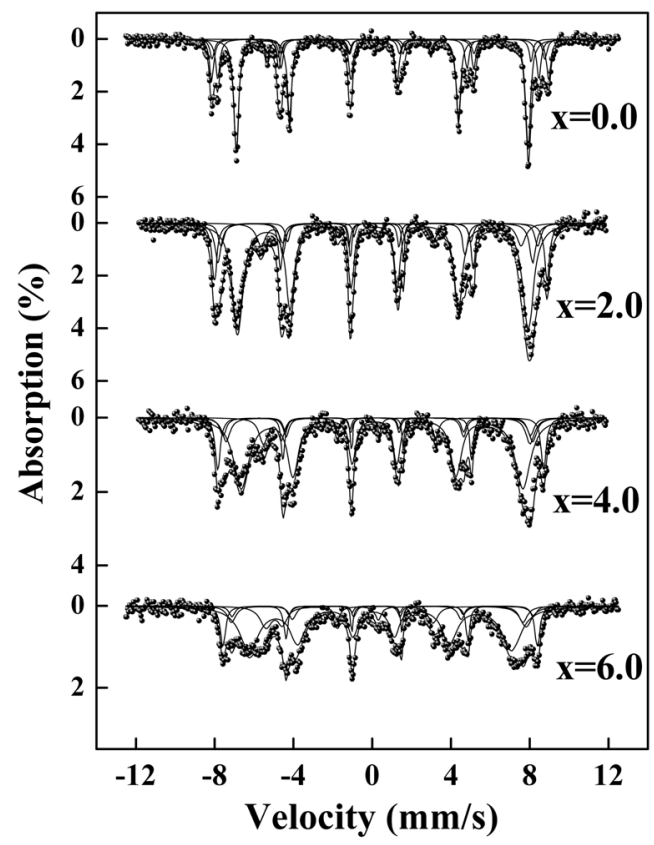

Fig. 3. Mössbauer spectra of $\mathrm{BaFe}_{12-x} \mathrm{Mn}_{x} \mathrm{O}_{19}(0.0 \leq x \leq 6.0)$ at $200 \mathrm{~K}$.
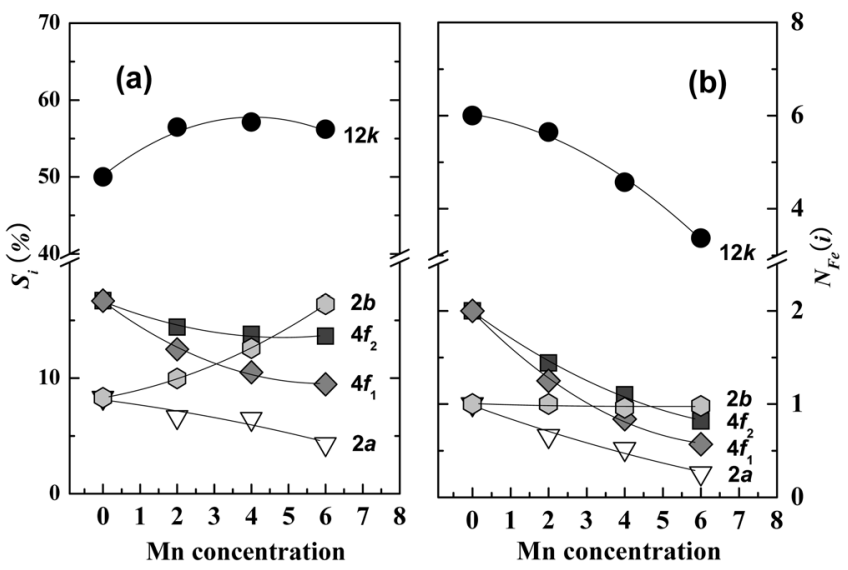

Fig. 4. (a) The relative areas $S_{i}$ in each site by Mössbauer spectra and (b) the occupation number of $\mathrm{Fe}$ ions in the five sublattices for $\mathrm{BaFe}_{12-x} \mathrm{Mn}_{x} \mathrm{O}_{19}(0.0 \leq x \leq 6.0)$.

$$
N_{\mathrm{Fe}}(i)=C_{\mathrm{Fe}} \frac{S(i)}{\sum_{i=1}^{5} S(i)},
$$

Here, $C_{\mathrm{Fe}}$ is the composition of the $\mathrm{Fe}$ ions in a chemical formula and $N(i)$ is the occupation number of the atom in each site.

$$
N_{\mathrm{Mn}}(i)=N(i)-N_{\mathrm{Fe}}(i),
$$

The occupation fraction of $\mathrm{Mn}$ ions, $N_{\mathrm{Mn}}(i)$, in the sublattices can be described as

$$
F_{\mathrm{Mn}}(i)=\frac{N_{\mathrm{Mn}}(i)}{N(i)} \times 100 \% \text {. }
$$

The results are shown in Fig. 5. The number of Fe ions does not change for the $2 b$ site, but decreases for the $4 f_{1}$, $2 a$, and, $4 f_{2}$, sites with an increasing $x$. This indicates that $\mathrm{Mn}^{3+}$ ions preferentially occupy the $4 f_{1}, 2 a$, and $4 f_{2}$ sites.

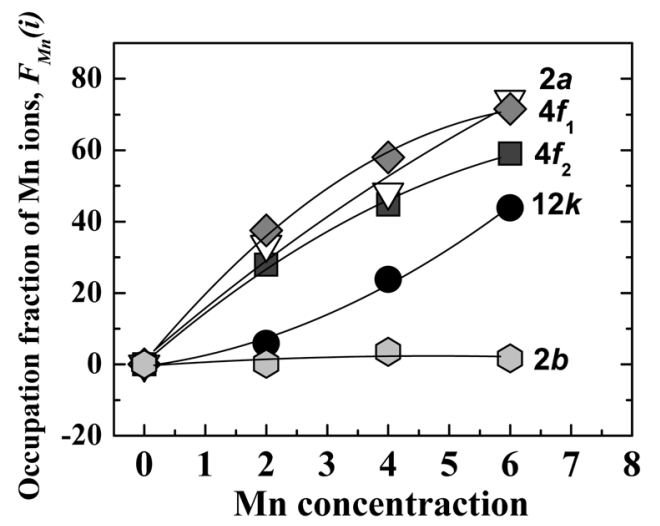

Fig. 5. The occupation fraction of $\mathrm{Mn}$ ions in the five sublattices for $\mathrm{BaFe}_{12-x} \mathrm{Mn}_{x} \mathrm{O}_{19}(0.0 \leq x \leq 6.0)$ by the relative area of subspectra. 
The relative areas of $\mathrm{BaFe}_{8} \mathrm{Mn}_{4} \mathrm{O}_{19}$ at various temperatures were $13.8 \%, 6.48 \%, 10.5 \%, 57.15 \%$, and $12.06 \%$ for $4 f_{2}, 2 a, 4 f_{1}, 12 k$, and $2 b$ subspectra, respectively. The isomer shifts, $\delta_{i}$ indicated that the valence state of all $\mathrm{Fe}$ ions were ferric $\left(\mathrm{Fe}^{3+}\right)$.

In summary, Mn-substituted Ba-ferrite powders have been synthesized by the HTTD method. The site occupancies [10], as determined with the Mössbauer spectra, show that the $\mathrm{Mn}^{3+}$ ions preferentially occupy the $4 f_{1}, 2 a$, and $4 f_{2}$ sites. The results show that the coercivity, magnetization and magnetocrystalline anisotropies are closely related to the distributions of $\mathrm{Mn}^{3+}$ on the five sublattices. This result demonstrates that the substitution of $\mathrm{Mn}$ ion on barium hexaferrite can be controlled for the magnetic properties induction of coercivities and the decrease of magnetization.

\section{Acknowledgment}

This work was supported by the Korea Science and Engineering Foundation (KOSEF) grant funded by the Korea government (MEST) (No. R01-2007-00020667-0).

\section{References}

[1] L. V. Saraf et al., Appl. Phys. Lett. 79, 385 (2001).

[2] N. Matsushita et al., J. Appl. Phys. 89, 6837 (2001).

[3] D. H. Choi, S. W. Lee, S. Y. An, S. I. Park, I. B. Shim, and C. S. Kim, IEEE Trans. Magn. 39, 2884 (2003).

[4] C. S. Kim, S. Y. An, J. H. Son, J. G. Lee, and H. N. Oak, IEEE Trans. Magn. 35, 3160 (1999).

[5] X. Z. Zhou, A. H. Morrish, Y. K. Hong, and Z. W. Li, IEEE Trans. Magn. 27, 4654 (1991).

[6] X. Z. Zhou, A. H. Morrish, Z. Yang, and H. X. Zeng, J. Appl. Phys. 75, 5556 (1994).

[7] Z. W. Li, C. K. Ong, Z. Yang, F. L. Wei, X. Z. Zhou, J. H. Zhao, and A. H. Morrish, Phys. Rev. B 62, 6530 (2000).

[8] S. Sun et al., J. Am. Chem. Soc. 124, 8204 (2002).

[9] Z. Yang, H. Zeng, D. Han, J. Liu, and S. Geng, J. Magn. Magn. Mater. 115, 77 (1992).

[10] I. J. Park, C. S. Park, K. S. Kang, and C. S. Kim, J. Magnetics 13, 110 (2008). 